\title{
Ablation of the Thyroid Remnant and I-I3 I Dose in Differentiated Thyroid Cancer: A Meta-Analysis Revisited
}

\author{
Suhail A.R. Doi, PhD, FRCP; Nicholas J. Woodhouse, FRCP;
} Lukman Thalib, PhD; and Adedayo Onitilo, MD, MSCR, FACP

Keywords:

Meta-analysis

Postoperative ablation

Radioiodine

Recurrence

Thyroid cancer

Thyroglobulin
Reprint Requests:

Suhail A.R. Doi, PhD, FRCP

Department of Medicine (Endocrinology) Mubarak Al-Kabeer Teaching Hospital and Kuwait University

Kuwait

Tel.: $+965688-6335$

Fax: +44 (709) 237-7990

Email: sardoi@gmx.net
Received: April 3, 2007

Revised: April 5, 2007

Accepted: April 13, 2007

doi: $10.3121 / \mathrm{cmr} .2007 .763$
$\mathrm{P}$ ostoperative ablation of functioning thyroid tissue has become established in the management of differentiated thyroid cancer as the long-term risk of recurrence and death is reduced. This beneficial effect results from the destruction of potentially malignant cells or occult multifocal disease that may occur in up to $30 \%$ of patients with papillary tumors ${ }^{1-4}$ Furthermore, the specificity of thyroglobulin as a tumor marker is increased and the sensitivity of subsequent whole body scans seems improved because residual thyroid tissue may compete with recurrent or metastatic thyroid cancer cells for radioiodine uptake. ${ }^{5}$ Indeed, it has been demonstrated that patients with successful ablation of remnant thyroid tissue have a better prognosis than those with unsuccessful ablation (disease-free survival of $87 \%$ versus $49 \%$ after 10 years, while thyroid cancer-related survival was $93 \%$ versus $78 \%$ ). ${ }^{6}$ This suggests that it is important to achieve complete ablation as soon as possible after diagnosis in order to ensure the best possible prognosis for a patient.

In $2000,{ }^{7}$ we demonstrated that the optimal dose (specific activity of I-131 administered) required to achieve ablation is a high dose of approximately $100 \mathrm{mCi}$, and thus lower doses are not as beneficial as the conventional doses of 75 to 100 $\mathrm{mCi}(2775-3700 \mathrm{MBq})$ in terms of successful remnant ablation. Recently, Hackshaw et $\mathrm{al}^{8}$ carried out another meta-analysis including studies published since 2000, and surprisingly, report that from the published data it is not possible to reliably determine whether ablation success rates using $30 \mathrm{mCi}$ are similar to using $100 \mathrm{mCi}$. Our analysis ${ }^{7}$ published in 2000 predicted that the risk estimates were stable. We did not think additional data would refute these findings, but rather would further narrow down the confidence intervals (CI) of the risk estimate. Thus, we performed this analysis again using the same data extracted by Hackshaw et al. ${ }^{8}$

The methods used were the same as previously described ${ }^{7}$ and the quantification was on the dichotomous variable "risk of failure of remnant ablation after I-131." There were a total of 2,584 patients (as opposed to our previous report which consisted of 967 patients), and of these, 1,094 patients who were given low doses and 1,490 patients who were given high doses were extracted from the 22 datasets that contained both a low-dose and high-dose group as reported in the study by Hackshaw et al. ${ }^{8}$ Of these 22 datasets, six 


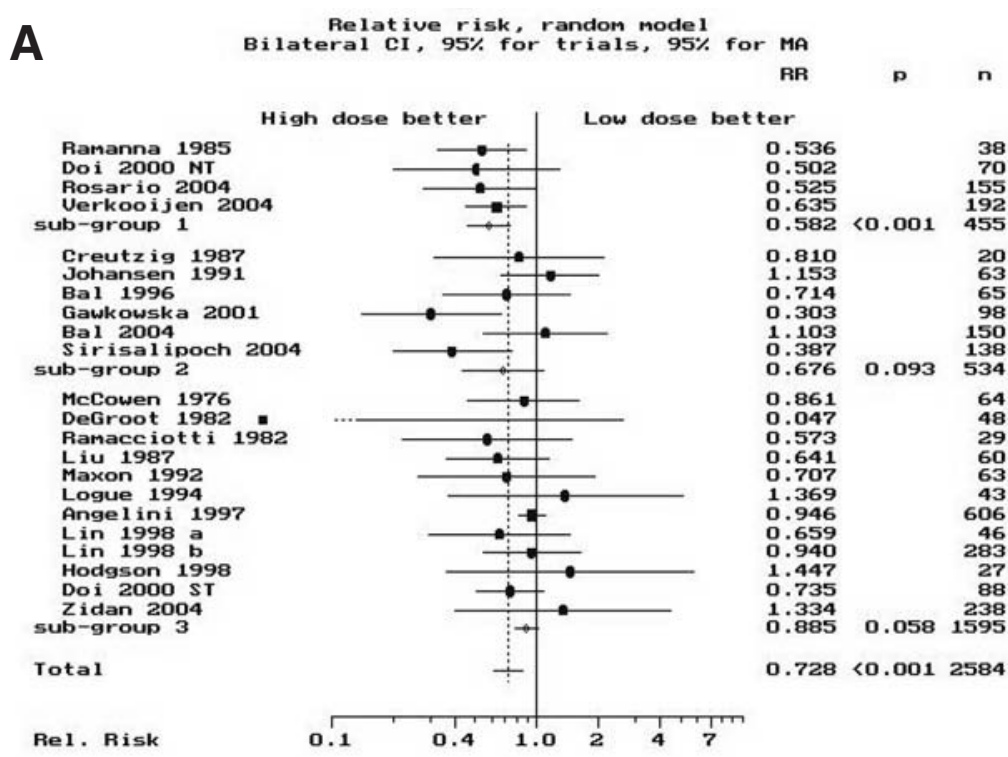

B

Relative risk, random model (Cumulative analys is)

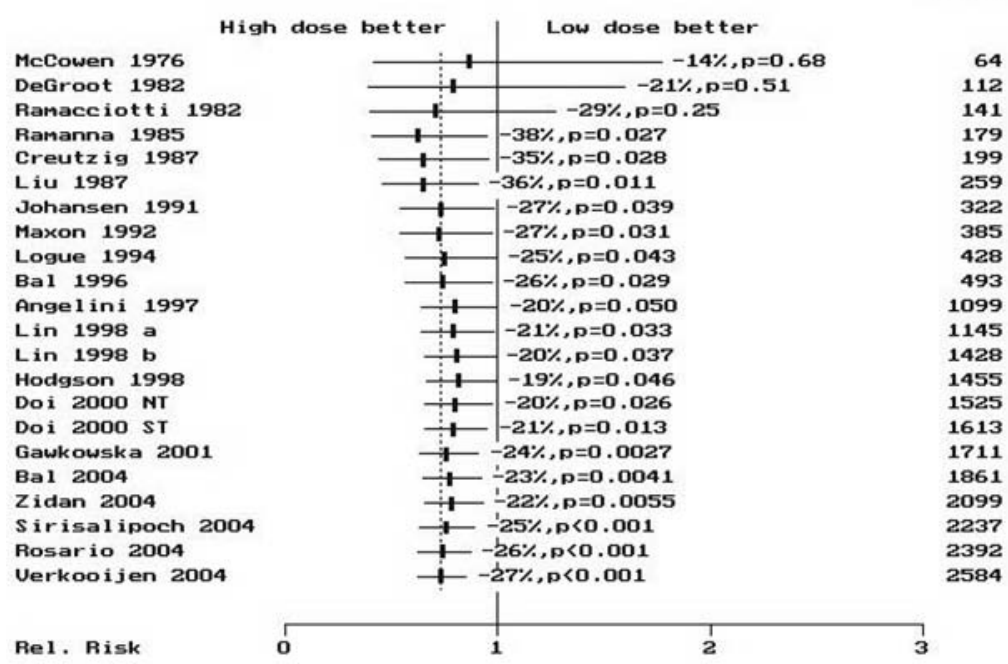

C Relative risk, random node1 (Cumulative analys is)

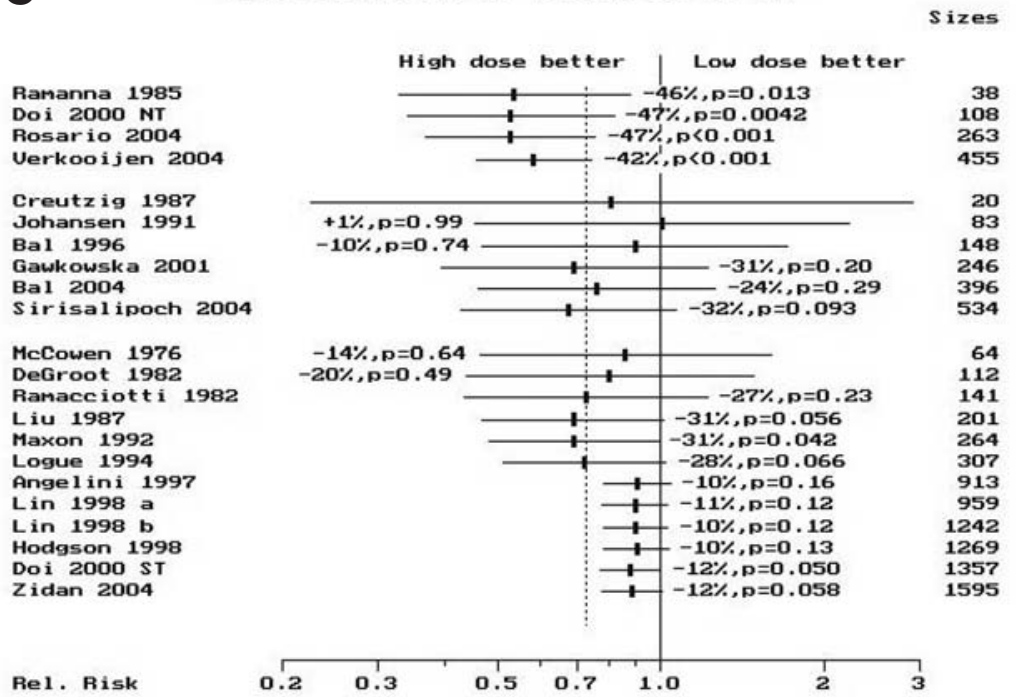

Figure 1. Standard meta-analysis and cumulative meta-analysis. (A) The standard meta-analysis plot of the risk ratios for non-ablation in a comparison of high-dose radioiodine (treatment group) with lowdose radioiodine (control group). The point estimates for the relative risk (RR) of each study and the pooled point estimate are shown by the vertical lines, while the horizontal lines show the confidence intervals $(\mathrm{Cl})$. " $\mathrm{n}$ " is the number of patients in each study. The summary RR is given for each group and "p" is the significance level. Group 1 contains cohorts with near-total surgery, group 2 contains the randomized controlled trials with mixed surgical status, while group 3 contains cohorts with mixed surgical status. The studies are ordered by year of publication. $\mathrm{RR}<1$ denotes a reduction in the number of failures in the high-dose group as compared with the low-dose group. The pooled RR for all studies (in both high-dose and low-dose groups combined) is indicated by "Total." The $\mathrm{Cl}$ of the estimate of the RR in the DeGroot ${ }^{28}$ study was wide $(95 \% \mathrm{Cl}, 0.001$ to 2.62$)$ as there were no failures in the high-dose group. As such, the $\mathrm{Cl}$ line was truncated as indicated by the dotted line ("..."). (B) The results of the cumulative metaanalysis of the same data. "Sizes" indicates the cumulative number of patients in the clinical studies. The points and lines represent the point estimates and the $95 \% \mathrm{Cls}$ of the pooled results after the inclusion of each additional study in the calculations. The studies have been sorted in order of year of publication. The Cls typically narrow with the addition of more studies over the years, suggesting that substantial heterogeneity does not exist. RR was plotted on a linear scale. (C) The results of cumulative meta-analysis by subgroup. The same conclusion persists, thus adding to the reliability of these results. RR was plotted on a log scale. "NT" indicates near-total surgery group (identified as "Woodhouse1" in Doi 2000 study). "ST" indicates subtotal surgery group (identified as "Woodhouse2" in Doi 2000 study). The letters "a" and "b" following "Lin 1998" identify two different studies by Lin published in 1998. 
were randomized controlled trials with mixed surgical status (group 2), ${ }^{9-14}$ four were cohorts with near-total thyroidectomy (group 1) $)^{7,15-17}$ and 12 were cohorts with mixed surgical status (group 3).7,18-28 Because of the concern about combining data from studies with markedly different designs, separate analyses were done for each group, as well as a pooled analysis. Since the test for heterogeneity was almost statistically significant (Cochran Q for heterogeneity, $P=0.08$ ), a random effects model was used as it does not assume that a common (fixed) treatment effect exists but rather that the true treatment effects in the individual studies may be different from each other. Such an analysis assumes the distribution of different true effects in each study is normally distributed, and we can estimate the summary of the different effects. However, we did not find a significant difference in results using a fixed or random effects model, and the CIs in the cumulative plot narrow with each additional study, suggesting that it may be reasonable to combine the studies into one stratum.

Most studies used a high dose of 2775-3700 MBq (75-100 $\mathrm{mCi})$. The summary high-dose to low-dose group relative risk (RR) of non-ablation after the first dose was 0.58 (95\% CI, $0.46-0.74)$ for the cohort studies in group 1 and 0.88 (95\% CI, $0.78-1)$ for those in group 3 using the random effects model. RR was 0.68 (95\% CI, 0.43-1.07) for the randomized controlled trials (group 2) using the random effects model. The subgroup summary and individual study RRs and 95\% CIs, listed by year of publication, are depicted individually in figure 1A. A cumulative analysis is depicted in figure 1B, while figure $1 \mathrm{C}$ displays the result of a cumulative analysis by subgroup. The pooled RR for all studies is 0.73 (95\% CI, $0.62-0.85$ ) which is identical to the risk estimate we reported previously $(\mathrm{RR}=0.73 ; 95 \% \mathrm{CI}, 0.61-0.87) .{ }^{7}$ This indicates that despite the inclusion of additional studies from the last 7 years, and more than doubling the patient pool, these estimates remain stable and affirm our previous findings. ${ }^{7}$ Thus, we cannot agree with the findings of Hackshaw et al. ${ }^{8}$ In summary, our analyses indicate that high-dose patients have about one-third less risk of non-ablation than low-dose patients, more so if extent of surgery is near-total and less so if incomplete surgery is performed.

We have not attempted here to redefine the pertinent issues in meta-analysis such as eligibility criteria, restriction of sample size or length of follow-up, eligibility based on similarity of treatments or outcomes or study quality, as these have been addressed in the original meta-analyses. ${ }^{7,8}$ Nevertheless, we must draw attention to a few important study differences that exist. The most important, as mentioned previously, is confounding caused by the extent of surgery. This, however, should bias the end result towards less effect for the high-dose group unless more patients with subtotal surgery were given lower doses. This seems unlikely as clinicians are prone to give higher doses to patients with subtotal surgery. However, as both high and low doses are less effective in less complete surgery, groups 2 and 3 demonstrate blunted risk differences.
An additional confounding factor would be the timing of post-ablation scans. If those patients given higher doses were scanned later than those given lower doses, a biased estimate of risk reduction could be determined. There was no reason to suspect that this had occurred in any study included in this analysis. One issue that certainly needs to be considered in the interpretation of this synthesis is the possibility of selection bias in the same direction across the studies, thus falsely exaggerating the risk estimates. In hospital-based cohort studies, it may be difficult to ensure comparability of the low-dose and high-dose groups, since selection bias as a result of unknown referral patterns cannot be easily overcome. However, we would assume that lower risk patients get lower doses and vice-versa, leading to non-differential bias resulting in a trend towards no difference rather than an exaggerated effect for higher doses. Finally, publication bias certainly may have influenced these results as indicated by Hackshaw et al, ${ }^{8}$ but this is a subject where negative results with larger doses would certainly qualify for publication due to the controversy that exists.

We would like to repeat our previous conclusion ${ }^{7}$ that, while it is true a higher dose means higher costs of admission to the hospital and patient inconvenience, comparing this and the rather insignificant side effects of the higher dose to that of a lower dose should focus in the first instance on an estimate of the benefits of successful ablation. Wong et $\mathrm{al}^{4}$ used a decision analytic perspective to determine that successful ablation probably reduces cancer recurrence rates by $54 \%$, and the change in life expectancy gained by successful ablation is about equal to that gained by coronary artery bypass graft in patients with two vessel coronary artery disease. The question of cost and inconvenience with high-dose therapy is similar to the question of choice of surgeon in coronary artery bypass graft. The stage of the tumor, extent of surgery and age of the patient are all factors in this decision-making process. We conclude that after increasingly meticulous near-total surgery and careful patient selection, the available data continue to favor higher doses of radioiodine (in the region of 2775-3700 MBq) for remnant ablation, especially after near-total thyroidectomy.

\section{References}

1. Mazzaferri EL, Jhiang SM. Long-term impact of initial surgical and medical therapy on papillary and follicular thyroid cancer. Am J Med 1994;97:418-428.

2. Simpson WJ, Panzarella T, Carruthers JS, Gospodarowicz MK, Sutcliffe SB. Papillary and follicular thyroid cancer: impact of treatment in 1578 patients. Int J Radiat Oncol Biol Phys 1988;14:1063-1075.

3. DeGroot LJ, Kaplan EL, McCormick M, Straus FH. Natural history, treatment, and course of papillary thyroid carcinoma. J Clin Endocrinol Metab 1990;71:414-424.

4. Wong JB, Kaplan MM, Meyer KB, Pauker SG. Ablative radioactive iodine therapy for apparently localized thyroid carcinoma. A decision analytic perspective. Endocrinol Metab Clin North Am 1990;19:741-760. 
5. Pagano L, Klain M, Pulcrano M, Angellotti G, Pasano F, Salvatore M, Lombardi G, Biondi B. Follow-up of differentiated thyroid carcinoma. Minerva Endocrinol 2004;29:161-174.

6. Verburg FA, de Keizer B, Lips CJ, Zelissen PM, de Klerk JM. Prognostic significance of successful ablation with radioiodine of differentiated thyroid cancer patients. Eur $\mathrm{J}$ Endocrinol 2005; 152:33-37.

7. Doi SA, Woodhouse NJ. Ablation of the thyroid remnant and 131I dose in differentiated thyroid cancer. Clin Endocrinol (Oxf) 2000;52:765-773.

8. Hackshaw A, Harmer C, Mallick U, Haq M, Franklyn JA. 131I activity for remnant ablation in patients with differentiated thyroid cancer: A systematic review. J Clin Endocrinol Metab 2007;92:28-38.

9. Creutzig H. High or low dose radioiodine ablation of thyroid remnants? Eur J Nucl Med 1987;12:500-502.

10. Johansen K, Woodhouse NJ, Odugbesan O. Comparison of $1073 \mathrm{MBq}$ and $3700 \mathrm{MBq}$ iodine-131 in postoperative ablation of residual thyroid tissue in patients with differentiated thyroid cancer. J Nucl Med 1991;32:252-254.

11. Bal C, Padhy AK, Jana S, Pant GS, Basu AK. Prospective randomized clinical trial to evaluate the optimal dose of $131 \mathrm{I}$ for remnant ablation in patients with differentiated thyroid carcinoma. Cancer 1996;77:2574-2580.

12. Gawkowska-Suwinska M, Turska M, Roskosz J, Puch Z, Jurecka-Tuleja B, Handkiewicz-Junak D, Wygoda Z, Jarzab B. Early evaluation of treatment effectiveness using 131I iodine radiotherapy in patients with differentiated thyroid cancer. Wiad Lek 2001;54:278-288.

13. Bal CS, Kumar A, Pant GS. Radioiodine dose for remnant ablation in differentiated thyroid carcinoma: a randomized clinical trial in 509 patients. J Clin Endocrinol Metab 2004;89:1666-1673.

14. Sirisalipoch S, Buachum V, Pasawang P, Tepmongkol S. Prospective randomised trial for the evaluation of the efficacy of low vs high dose I-131 for post-operative remnant ablation in differentiated thyroid cancer. World J Nuclear Med 2004; 3:S36 [Abstract].

15. Rosario PW, Reis JS, Barroso AL, Rezende LL, Padrao EL, Fagundes TA. Efficacy of low and high 131I doses for thyroid remnant ablation in patients with differentiated thyroid carcinoma based on post-operative cervical uptake. Nucl Med Commun 2004;25:1077-1081.

16. Ramanna L, Waxman AD, Brachman MB, Tanasescu DE, Sensel N, Braunstein GD. Evaluation of low-dose radioiodine ablation therapy in postsurgical thyroid cancer patients. Clin Nucl Med 1985;10:791-795.

17. Verkooijen RB, Stokkel MP, Smit JW, Pauwels EK. Radioiodine-131 in differentiated thyroid cancer: a retrospective analysis of an uptake-related ablation strategy. Eur J Nucl Med Mol Imaging 2004;31:499-506.

18. Hodgson DC, Brierley JD, Tsang RW, Panzarella T. Prescribing 131Iodine based on neck uptake produces effective thyroid ablation and reduced hospital stay. Radiother Oncol 1998;47:325-330.

19. Angelini F, Capezzone M, Cecarelli C, Lippi F. Comparison among different 1311 activities for ablation of post-surgical thyroid residues. In: Hennemann G, ed. Thyroid International, Report of the 24th annual meeting of the European Thyroid Association. Darmstudt, Germany: Merck KgaA, No. 6-1997.

20. Zidan J, Hefer E, Iosilevski G, Drumea K, Stein ME, Kuten A, Israel O. Efficacy of I131 ablation therapy using different doses as determined by postoperative thyroid scan uptake in patients with differentiated thyroid cancer. Int J Radiat Oncol Biol Phys 2004;59:1330-1336.
21. Maxon HR 3rd, Englaro EE, Thomas SR, Hertzberg VS, Hinnefeld JD, Chen LS, Smith H, Cummings D, Aden MD. Radioiodine-131 therapy for well-differentiated thyroid cancer - a quantitative radiation dosimetric approach: outcome and validation in 85 patients. J Nucl Med 1992; 33:1132-1136.

22. Logue JP, Tsang RW, Brierley JD, Simpson WJ. Radioiodine ablation of residual tissue in thyroid cancer: relationship between administered activity, neck uptake and outcome. Br J Radiol 1994;67:1127-1131.

23. Liu RT, Huang MJ, Huang HS, Huang BY, Lin JD, Wang PW, Tzen KY. Comparison of 30mCi and higher doses of iodine-131 for postoperative thyroid remnant ablation. Taiwan Yi Xue Hui Za Zhi 1987;86:524-528.

24. Lin JD, Kao PF, Chao TC. The effects of radioactive iodine in thyroid remnant ablation and treatment of well differentiated thyroid carcinoma. Br J Radiol 1998;71:307-313.

25. Ramacciotti C, Pretorius HT, Line BR, Goldman JM, Robbins J. Ablation of nonmalignant thyroid remnants with low doses of radioactive iodine: concise communication. J Nucl Med 1982;23:483-489.

26. McCowen KD, Adler RA, Ghaed N, Verdon T, Hofeldt FD. Low dose radioiodide thyroid ablation in postsurgical patients with thyroid cancer. Am J Med 1976;61:52-58.

27. Lin JD, Chao TC, Huang MJ, Weng HF, Tzen KY. Use of radioactive iodine for thyroid remnant ablation in well-differentiated thyroid carcinoma to replace thyroid reoperation. Am J Clin Oncol 1998;21:77-81.

28. Degroot LJ, Reilly M. Comparison of 30- and 50-mCi doses of iodine-131 for thyroid ablation. Ann Intern Med 1982;96:51-53.

\section{Author Affiliations}

Suhail A.R. Doi, PhD, FRCP

Department of Medicine (Endocrinology)

Mubarak Al-Kabeer Teaching Hospital and

Kuwait University, Kuwait

Nicholas J. Woodhouse, FRCP

Department of Medicine (Endocrinology)

Sultan Qaboos University, Oman

Lukman Thalib, PhD

Department of Community Medicine (Biostatistics)

Kuwait University, Kuwait

Adedayo Onitilo, MD, MSCR, FACP

Marshfield Clinic Weston Center

Weston, Wisconsin, USA 